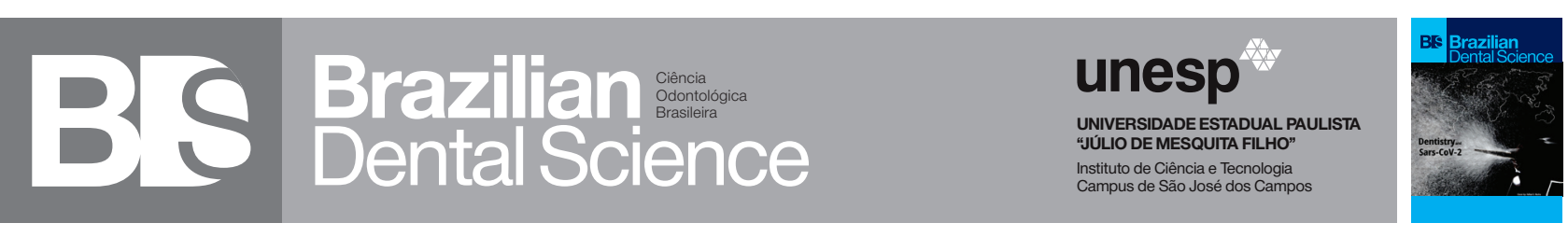

\title{
Protocols to control contamination and strategies to optimize the clinical practice in Restorative Dentistry during the COVID-19 pandemic
}

Protocolos para controle de contaminação e estratégias para otimizar a prática clínica em Odontologia Restauradora durante a pandemia de COVID-19

Ana Luiza Barbosa JUREMA ${ }^{1}$, Rafael Santos ROCHA ${ }^{2}$, Mariane Cintra MAILART ${ }^{2}$, Maurício Yugo de SOUZA ${ }^{3}$, Sérgio Eduardo de Paiva GONÇALVES ${ }^{2}$, Taciana Marco Ferraz CANEPPELE ${ }^{2}$, Eduardo BRESCIANI ${ }^{2}$

1 - Paulista University (UNIP) - Health Sciences Institute - São José dos Campos - SP - Brazil.

2 - São Paulo State University (Unesp) - Institute of Science and Technology, São José dos Campos - Department of Restorative Dentistry - SP - Brazil.

3 - ICESP University (UNICESP) and Euro-American University (UNIEURO) Brasília - DF - Brazil.

\begin{abstract}
The current outbreak of coronavirus 2019 (COVID-19) challenges how professional standards have been defined so far. In Dentistry, biosafety measures already taken by professionals have been intensified, aiming to offer the patient urgent and emergency treatment with safety for both. In this context, Restorative Dentistry is responsible for the care of patients with caries injuries, with or without symptoms and, fractures of teeth and existing restorations. This article guides professionals, during the pandemic period, on the risks involved in adult and pediatric dental care for patients with restorative needs. It also discusses strategies to optimize clinical practice, reducing risks of contamination and virus transmission.
\end{abstract}

\section{KEYWORDS}

Operative Dentistry; Dentistry; Biosafety; Pandemics; COVID-19.

\section{RESUMO}

O atual surto de coronavírus 2019 (COVID-19), fez com que muitos profissionais repensassem sua postura de trabalho. Na Odontologia, medidas de biossegurança já realizadas pelos profissionais, foram intensificadas, com o objetivo de oferecer ao paciente um tratamento de urgência e emergência com segurança para ambos. Neste contexto, a Odontologia Restauradora é responsável pelo atendimento de pacientes com lesões de cárie, com ou sem sintomatologia, e fraturas de dentes e restaurações já existentes. Este trabalho orienta os profissionais quanto aos riscos envolvidos no atendimento odontológico, adulto e pediátrico, de paciente com necessidades restauradoras durante o período de pandemia. $\mathrm{O}$ artigo também discute estratégias para otimizar o atendimento, diminuindo riscos de contaminação e transmissão do vírus.

\section{PALAVRAS-CHAVE}

Dentística, Odontologia; Biossegurança; Pandemias; COVID-19. 


\section{INTRODUCTION}

$T$ he coronavirus disease, also called 1 COVID-19, emerged in December 2019, in Wuhan, China [1]. This highly contagious disease spread quickly throughout the country's territory. Then, it has become a serious challenge for public health around the world when reached the pandemic level [2]. The etiological agent of COVID-19 is the SARS-CoV-2 (Severe Acute Respiratory Syndrome Coronavirus 2) and its transmission occurs mainly via respiratory droplets and direct interpersonal contact [3].

Some clinical manifestations of COVID-19 are fever, cough, headache, sore throat, rhinorrhea, chest pain, diarrhea, and nausea and vomiting [4]. Besides these manifestations, a substantial proportion of patients can be asymptomatic or present few of the symptoms. The sudden onset of the loss of sense of smell or taste can occur even if not associated with nasal congestion, considering it has neurological origin $[5,6]$. The period from the infection to the first symptoms manifestation, the incubation period, can last up to 14 days [7]. Therefore, it is difficult to monitor the disease, which may lead to fast and increased spread.

Considering this context, many health services had to readjust their activities. For the dental care, the risk of cross infection among professionals and patients is considerable, due to direct contact with saliva and increased aerosol production [8]. Each country has its specific quarantine measures and in most of them, for dentists, the instruction is only to provide emergency and urgency care [9].

The restorative dentistry includes some urgent procedures that may be needed during the social isolation period. Restorative techniques should be performed with maximum simplification, with reduced clinical steps and consequently decreased clinical appointment time. These actions lead to reduced aerosol production and less contaminated surfaces and instruments. Although there is a great risk of infection in dental clinics, professionals should work with assurance, because there are biosafety guidelines and measures to protect then, their team and patients $[8,10-15]$.

\section{Remote monitoring by Teledentistry}

With the rapid spread of Covid-19 and increased risk of cross infection, it was recommended that people avoid hospital, medical and dental offices because they could be substantial sources of contagion $[16,17]$. Therefore, it is important to focus on alternatives for assistance and treatments to avoid face-to-face contact between health professionals and patients [17].

Between the alternatives, the telemedicine is a concept of remote healthcare. It can be an effective methodology to provide medical assistance through communication technologies, as smartphones, tablets, and laptops [16, 18].

For dentistry, the risk of contagion is even greater, due to direct contact with the patient's saliva. Then, remote communication might help to contain the spread of infection. For that, there is the teledentistry, a domain of telemedicine specifically targeted for dental care. This approach can connect dentists and patients in situations there is no possibility of personal meetings using the technology [19].

Teledentistry may be an important tool to decrease the risk of contagion, because it avoids patients to move to dental offices without an effective indication, it limits the human contact between dental team and patient, and it reduces the crowding of people in waiting rooms [16].

The literature regarding the efficiency of teledentistry is inconsistent $[19,20]$. Although this modality of remote assistance may not be the best means for a more accurate diagnosis and treatment, it increases the access to dental care, with the advantages of reduced time and good cost effectiveness [20]. Besides that, in the pandemic context, the teledentistry can help to monitor some oral conditions (post-operative conditions, sensitivity, manifestations of allergic or herpetic reactions, for example) and to provide preventive care (oral hygiene and diet consulting). Moreover, it is possible to prepare treatment plannings, to screen patients who really need face-toface treatment, and to guide those who do not need to come to the office in a didactic way $[16,19]$. 
Despite being a good alternative for dental care, professionals should pay attention to the rules and guidelines for dentistry of each country, because some locations do not provide regulations for this modality of care.

Understanding the main risks of the main protocols in Restorative Dentistry

Dental emergencies associated with restorative procedures like pain related to reversible pulpitis, extensive caries lesions, and dental or restorative fracture may occur during this period [8]. Those events require professional intervention for correct pain management and problem resolution. In this context, this topic aims to discuss clinical situations relevant to Restorative Dentistry, and to address strategies to reduce the risk of contagion and virus transmission.

\section{Personal Protective Equipment (PPE)}

COVID-19 presents a primary mode for transmission and infection by saliva droplets, so the closer the contact the greater the chances of contamination, as stated by World Health Organization (WHO) [10]. This information corroborates with the results of To et al., 2020 [21], who evaluated saliva samples from patients with COVID-19 and in $91.7 \%$ of the evaluated patients the presence of the virus was detected. That observation indicates a possible reservoir of virus in the salivary glands [21]. Based on that, an asymptomatic patient may be a vector for COVID-19 contamination and therefore, it is necessary the use of PPE and effective methods, like rubber dam, to minimize the risk of contamination.

The use of PPE is a practice to prevent infection that applies to all patient care, regardless of the asymptomatic or confirmed infection status, for any delivered dental care. According to Centers for Disease Control and Prevention (CDC) guidance, the recommendation of PPE use for dentists and staff during treatment is strongly advised. Those include working clothes (coat) with disposable isolation clothing or surgical clothes as and outer layer protective eyewear, masks (N-95 mask and surgical mask), disposable latex gloves and caps, face shields to protect mucous membranes of the eyes, nose, and mouth, and protective outerwear during procedures that likely generate splashing or spattering of saliva or other body fluids [22, 23]. According to the CDC guidance, it is also recommended to safely discard and to replace masks if it is damaged or not clean, or if breathing through is difficult [22]. It is recommended everyone should be wearing a mask of any type, before and after the treatment session.

\section{Rubber dam isolation}

Other recommended procedure for dentists, is the use of rubber dam for all aerosol-producing protocols, in order to minimize the risk of contamination by reducing the production of aerosols or spatter [22]. The referenced procedure minimizes the production of saliva and blood spatter when high-speed handpieces are used. In addition, it minimizes the possible contact with gingival fluid or breathing, and consequently the COVID-19 contamination $[22,11]$, once there is a $70 \%$ reduction of airborne particles within the one meter diameter of the operatory field [11].

\section{High-speed handpiece}

Infected patients present a high potential for infection spreading, considering the conditions of the oral cavity, in which saliva is highly contaminated with virus [4, 21]. Several therapies based on mouthwashing procedures prior to treatment have been studied to test a possible decrease in salivary viral load. However, there are no conclusive data on the effectiveness of the tested products [24]. Thus, the use of mouthwash could give the professional a false sense of security. In addition, the salivary glands would continue to produce saliva with the potential for infection throughout the dental procedure $[4,21]$.

Another factor of concern is that approximately one third of infected patients do not show symptoms of the disease, and therefore, they are not aware they are potential transmitters of the virus [15]. Therefore, all patients should be treated as potential focus for transmission.

Thus, one of the main impacts on the practice of Restorative Dentistry during the 
pandemic is to eliminate the use of rotary instruments during dental procedures, since these devices are used inside the oral cavity, in contact with contaminated fluids, favoring the spread of the virus, and potential for contamination of the environment and / or dental personnel and patients [25].

The aerosol formed during dental service by the handpiece (Figure 1) is capable to spread and to contaminate the entire room $[25,26]$. A study that evaluated the distance bacteria can be transported and spread through the air concluded that microorganisms could reach a distance greater than $1.5 \mathrm{~m}$ [25]. However, with aerosol formation, the potential for contamination prolongs for $h$ [26], and the spread can be even greater.

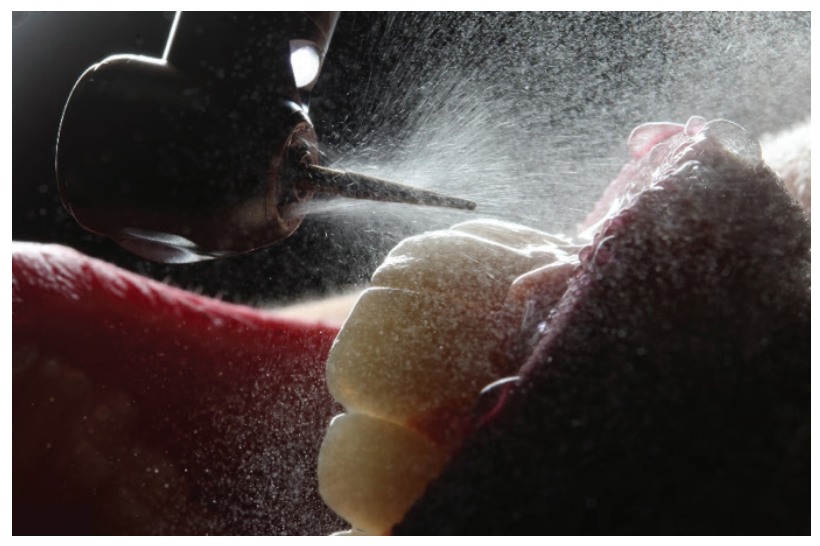

Figure 1- Figure showing the aerosol formed during the use of dental high speed handpiece with water spray.

Data that assessed the potential for spreading viruses by aerosols from turbines of handpieces are scarce in the literature. However, if we take into account that the virus has a more reduced size and weight than bacteria, the whole room could be contaminated after using the rotary instrument with water spray.

It is known that the main form of contamination is through inhalation of the virus [27]. It is estimated that when a person speaks out loud for 60 seconds, droplets generated in the air remain in suspension for about $8 \mathrm{~min}$, with the potential for contamination when inhaled by a healthy patient [27]. In the dental environment, the time that the virus can be suspended in the air, when a rotating instrument with irrigation is used, can be even more worrying [26].

Van Doremalen et al., 2020 [26], evaluated, under experimental conditions, the time that the contaminated aerosol can remain viable and infectious in the air. According to the authors, SARS-CoV-2 could contaminate a person who inhaled ambient air for the entire duration of their experiment $(3 \mathrm{~h})$. However, at the end of the analysis time, the amount of viruses with potential for contamination suspended in the air was high, which suggests that this time is even greater.

Another fact that can generate aerosol during dental care is the use of air-water syringe under the spray option [28]. In this way, if the cavity needs to be cleaned, the ideal would be to use cotton pellets soaked in water.

Portable devices that sterilize air by UV light in hospital rooms and dental clinics are gaining place, especially after the risk of aerosol air contamination is knwon.

In this way, knowing that the aerosol has a great spreading potential and it can remain infectious for hours, the ideal is that all objects on furniture and benches are stored in airtight boxes, preferably stored inside closed cabinets. The professionals should leave out of closed compartments only the necessary for their use. Aerosol should be avoided, and if its use is of extreme importance, the professional should use all necessary protective measures and perform the service at the end of the working day. Thus, until the following day, the potential for aerosol suspended in the air would be minimal or non-existent, and the decontamination of the room could be carried out more safely.

Restoration in posterior teeth with Glass Ionomer Cement (GIC) and Atraumatic Restorative Treatment (ART)

If a restoration in posterior teeth is required, the operator needs to consider methods to minimize possible contamination by Sars-CoV-2 (COVID-19). By knowing that the greatest risk of operator's contamination is through aerosol, the most indicated is to 
perform ART, in which hand instruments substitute the rotary instruments used in the conventional technique (drill and fill). According to a meta-analysis, the ART treatment presents satisfactory clinical longevity mainly for simple-surface restorations, around $87.1 \%$ after 3 years [29]. Moreover, ART is indicated for children or adults as it presents less potential to cause discomfort and anxiety for patients [30]. It may be considered the best treatment option for this pandemic time, once ART is less sensitive and it can be performed by all dentists, whether being a specialist or not [31].

In Restorative Dentistry, there is a consensus that the selective removal of carious tissue is the best way to prevent accidental pulp exposure, especially in deep cavities. The soft tissue left at the bottom of the cavity does not negatively influence the longevity of the restoration, since the supply of fermentable carbohydrates and maturation of the biofilm is inhibited [32, 33]. It is solely required to completely remove the dentin affected by bacteria from the surrounding walls, since this improves cavity sealing. The main idea of employing this technique is based on the fact it requires only hand excavators, generating no aerosol, and the non-exposed pulp scenarios resulted from the technique prolong the tooth lifespan and limits the necessity of endodontic interventions with possible need of using dental handpieces.

GIC restorations of class II cavities are also supported by the literature. They present adequate success rates, while only the esthetic parameters (color match and marginal discoloration) are reported to differ after ten years follow-up [34,35]. Moreover, some studies concluded that GIC restorations presented low microleakage level regardless the GIC composition, if conventional or resinmodified $[36,37]$, added to the fact GIC favors the remineralization of adjacent tissues as a result of the release of fluoride. It is important to emphasize that, regardless the material used, the operator needs to perform the correct proportion, manipulation and insertion of the material in the cavity. The manufacturer's recommendations should be followed to obtain a GIC with the proper properties and consequently high longevity.

Otherquestions involving GIC are theneed to use a mixing device under the mechanical manipulation and photopolymerization process, once in each of those steps the operator needs to use a different equipments and need to follow the disinfection protocol to avoid cross contamination.

Finally, it is indicated the operator detects, during the clinical examination, initial injuries through an accurate diagnosis. The caries activity and risk assessment should be verified in order to avoid the occurrence of new caries lesions [33]. Fluoride application for remineralization of initial lesions and reinforcement of oral hygiene should be provided. If necessary, sealing of small cavities involving dentin may be indicated $[32,33]$.

\section{teeth}

Fractures and restorations in anterior

Restorations in anterior tooth should be performed when a fracture of restoration or trauma occur, since these situations characterize an urgent procedure according to American Dental Association guidelines. The dental health and function should be restored, as well as the esthetic condition.

It is very important to consider simplified techniques to restore anterior teeth, in order to avoid aerosol formation and to limit the appointment time, as previously reported. For this procedure, the placement of bevel on enamel margins is conventionally required to enhance esthetics in restoration [38]. Nevertheless, with the aim to reduce the aerosol suspension and considering the main reason to perform a bevel, this restorative step could be avoided at this moment. The adhesive properties of actual materials are well reported with sufficient basis to provide proper adhesion $[38,39]$. Another important point to be highlighted is the choice of the adhesive system. For shorter clinical steps and to simplify the bonding procedure, a self-etch adhesive system seems to be more appropriate, as it presents lower technical sensitivity [40] and satisfactory clinical performance [41].

Techniques are available to restore anterior teeth with resin composites [42]. 
When the monochromatic layering is adopted, a single resin composite body shade is used with the great advantage of saving time. A satisfactory esthetic with this procedure can be achieved with adequate natural aspect [43]. At the end of restoration, the occlusal contacts need to be properly evaluated, avoiding future complication in this pandemic moment. It is important to guide the patient regarding habits that could generate a restoration fracture.

\section{Simplified restorative technique}

In pandemic context, the choice for urgent treatments should consider alternatives with simplified techniques. The elimination of steps, time reduction and use of less instrumental might contribute to the decrease of COVID-19 dissemination. It is important to highlight that simplified restorative protocols are well consolidated in dental literature. Between them, it is worth to mention some approaches about adhesive strategies, resin composite type, polishing procedures, GIC, radiographic exams evaluation and preventive treatment.

Self-etch adhesive systems can be used with a simplified application without the acid etching step [44]. One-step self-etch adhesive strategy associates the etching, priming and bonding in one procedure. It contains acidic functional monomers, hydrophilic and hydrophobic monomers, water and organic solvents into a single product [40]. With the presence of acidic monomers and the need of smear layer maintenance, the acid conditioning step is eliminated. This protocol reduces aerosol formation, as it is not necessary to rinse the dental surface after the phosphoric acid application, reducing the session time and the contact with other instruments.

For anterior teeth requiring restorative treatment, the use of body shaded resin might be a good alternative to optimize the procedure. These resin composites present an intermediate opacity, and thus it is possible to restore cavities with only one type of resin $[45,43]$. This makes the procedure faster and more practical, and it is not necessary to use and touch many materials.

After performing the restoration, the finishing and polishing steps also require care and should be simplified. More specifically, the reduced-step systems, that are the combination of the finishing and polishing procedures in one or two steps, are the best choices, as they present satisfactory results [46]. Once more, the elimination of steps and the use of fewer materials help for the decrease of virus contagion.

For the use of GIC in ART for final or temporary restorations in posterior teeth, the choice for chemically cured materials could simplify the procedure, due to as there is no need of to use LED-curing light equipments use. It Those steps avoids the contact with other equipments during clinical procedures and prevents contamination with patient saliva.

Although it is not possible to avoid urgent situations in Restorative Dentistry, some dental problems could be prevented with the adequate guidance of professionals. Patients not under urgent situations can be monitored and guided by professionals with telephone assistance or using communication apps, for example. The aims are to alert the importance of care with oral hygiene, healthy habits and adequate diet during this period. It can prevent urgent situations and avoid the displacement of the dental team and of patient to dental office.

\section{Radiographs}

Another concern dentists should be aware during this period is the need for intra-oral radiographic examinations. While performing this examination, all care must be taken to avoid contamination, through contact with saliva, of objects like: x-ray apparatus, lead apron, radiographic sensor or film, film holders, and development booth [47-49].

The film and/or sensor should preferably be protected with a plastic or disposable latex cover $[47,49]$. After the $\mathrm{x}$-ray take, non-sterilizable intraoral devices for digital radiography and conventional radiographic films require rigorous decontamination after use, since both the digital radiography sensor and the radiographic film have direct contact with the patient's saliva [47]. 
The dentist should preferably wear disposable gloves when making dental radiographs, aiming not to touch the equipment with the glove contaminated by handling the film in the patient's mouth [48]. It is also recommended to protect the X-ray equipment with plastic that can be disposed after the use [48]. In addition, the professional must thoroughly clean the hands before and after the examination, as a possible contamination may happen when touching the outside of the gloves when putting on and removing them [48].

In this context, during this period, extraoral radiographs (panoramic radiography), even though they are not the first choice for many procedures in Restorative Dentistry, they can assist the diagnosis and the therapeutic decision with less chance of risk.

\section{Pediatric patients}

The control of COVID-19 spread is also a responsibility of professionals who must carry out emergencies and urgent dental care, postponing elective procedures to minimize the contamination risk. The transmission of infection from dental procedures needs to be considered not only for vulnerable adults but also for children. Considering the pediatric dentistry, parents should also be included in the infection control practices. According to American Academy of Pediatric Dentistry [50], it is recommended that only one guardian must accompany the child and with the proper use of a mask. Additionally, whenever possible, the physical behavior guidance should be postponed.

The early childhood caries is a common disease that affects around $60-90 \%$ of children in the primary dentition in developing countries [51]. Urgency procedures related to this condition may occur in scenarios of pain or sepsis, if no intervention is performed [52]. The restorative treatment must be optimized, aiming to reduce the steps of the restorative procedure and number of patient's visit for dental appointments. The ART is the most indicated technique to be performed in posterior teeth since it minimizes the aerosol formation [30]. Considering the quality of life, pediatric dentists have the responsibility to guide the families about feeding information aiming to strengthen the immune system and prevent dental caries [53]. The professionals have the option to guide and monitor the families of their pediatric patients regarding the eating habits and to motivate the maintenance of oral hygiene thorough video calling apps, as it seems to be an effective way to prevent others dental complications. Additionally, it is important to emphasize to parents that just dental emergencies, as pain, infection or trauma, must be treated.

\section{Disinfection and sterilization procedures}

Not only the procedures have to be involved in this contamination control, but also the clinical sanitization is an important factor that contributes for patients and dental team care. Different protocols of disinfection are adopted, according to the type of surface that can be disinfected or sterilized [12]. In this pandemic moment, an effective broad spectrum of microbicide activity cleaning and disinfection practices prevent crosscontamination, since the virus persists on metal, glass or plastic surfaces around 9 days, considering a room temperature [13].

The surfaces are categorized into three groups according to the degree of contamination: critical, semi-critical and noncritical [12,54]. The first group, critical surfaces, involved objects that must be sterilized since they present a high risk of infection transmission. The objects presenting heat-sensitive characteristics, a sterilizing chemical liquid is an important option to be used or ethylene oxide or hydrogen peroxide gas are other options. The disadvantage of the chemical liquid is that after the sterilization process, the object should be submitted to a rinsing with water, and then, this method has to be considered when the other sterilizing options are impossible to be performed [54].

Semi-critical surfaces contact mucous membrane or nonintact skin, and for those objects, a high-level disinfection is required. The most common solutions chosen for these objects are hydrogen peroxide, glutaraldehyde, peracetic acid, and phenol solutions [12]. 
Furniture, floors, door handles, chairs, desks, and bathroom present surfaces considered noncritical items of the dental office, since they do not contact mucous membrane or nonintact skin. Nevertheless, these objects contribute to a contamination through contact by hand between patients and dental team. It is recommended that the noncritical surface should be cleaned using water and detergent, followed by the application of a hospitallevel disinfectant, as this combination shows satisfactory effectiveness [13, 14]. The most indicated hospital-level disinfectant is $0.05 \%$ sodium hypochlorite solution, according to World Health Organization. This solution should be applied on the floor and after each appointment.

Considering small surfaces, $70 \%$ ethanol solution should be used. It is available in the market the "ready to use" disinfectant wipes impregnated with alcoholic solution or other chemical products (chlorine, peroxygens, and quartenary ammonium compounds) [55]. The advantage is to facilitate the cleaning process on small surfaces, decreasing the possibility of inhalation. Nevertheless, there is no consensus in the literature regarding this effectiveness, since some solutions can evaporate from the wipe and the biocide activity could be compromised [55]. The exposure time required for these solutions to act is at least 60 s or longer [54]. Moreover, items present in the waiting rooms such as toys, magazine and books should be removed. In the waiting room, alcohol-based hand rub with 70\% alcohol at entrances should be offered for patients.

In between patients, the personal protective equipment (operator and patients) as protective eyewear of face shields should be cleaned with soap and water. Handpieces, dental x-ray equipment, dental chair should follow the cleaning recommendations provided by manufacturers. After the dental debris removal, the handpiece needs to be submitted to heat sterilization after each patient. Handpiece devices include highspeed, low speed, endodontic, electric and surgical handpiece. It is very important to consider that if any dental handpiece cannot be submitted to heat sterilization, it must not be used in the dental procedure, according to Centers for Disease Control and Prevention [22]. Additionally, although there is no standardized time interval between patients dental treatment, it is important to consider that the virus maintaining its viability in the air at least for $3 \mathrm{~h}$ [26] when aerosol is generated. This time should be considered in the patient appointments with a cleaning schedule to maintain an effective disinfection procedure in the dental office. Moreover, the proper cleaning guidance for both dental staff and patients will contribute to the effective controlling of COVID-19 contamination.

\section{Conclusions and perspectives}

The practice of dentistry during the COVID-19 pandemic, besides biosafety measures especially related to aerosol and the spacing between patients, indicates the use of simplified procedures that are based on the concept of minimally invasive dentistry. Perhaps, this need is an opportunity for a paradigm shift within dentistry with the adoption of more biological techniques, even after the pandemic has passed. The gap between science and practice, especially regarding the procedures proposed here, as ART and selective caries removal, have been discussed for some time.

Dentistry has always been grounded and focused on hygiene and cross-contamination control procedures to ensure safety to the patients and professionals. The emergence of other viruses in the past, such as the Human Immunodeficience Virus (HIV) has changed our hygiene and sterilization routines. And the same is happening now, with care under intensified biosafety. The support of science is essential until there is a return to normality. Research is being carried out to clarify what needs to be improved in clinical care to ensure safety for everybody. The attitudes mentioned here aim to contribute to this safe operation. However, for sure, the improvement of biosafety will be permanently incorporated into routine procedures. In case biosafety measures are still neglected by professionals, conscious patients could set this condition as a prerequisite for selecting their health care providers. 


\section{REFERENCES}

1. WuF, Zhao S, Yu B, Chen YM, Wang W, Song ZG, et al. new coronavirus associated with human respiratory disease in China [published correction appears in Nature. 2020 Apr;580(7803):E7]. Nature. 2020;579(7798):265-69. doi:10.1038/s41586-020-2008-3

2. Mahase E.China coronavirus: WHO declares international emergency as death toll exceeds 200. BMJ. 2020;368:m408. Published 2020 Jan 31. doi:10.1136/ bmj..m408

3. Special Expert Group for Control of the Epidemic of Novel Coronavirus Pneumonia of the Chinese Preventive Medicine Associaton. An update on the epidemiological characteristics of novel coronavirus pneumonia (COVID-19). Zhonghua Liu Xing Bing XueZaZhi. 2020;41(2):139-44. doi:10.3760/cmaj.jis sn.0254-6450.2020.02.002

4. Chen N, Zhou M, Dong X, Qu J, Gong F, Han Y, etal. Epidemiological and clinical characteristics of 99 cases of 2019 novel coronavirus pneumonia in Wuhan, China: a descriptive study. Lancet. 2020;395(10223):507-13. doi:10.1016/S01406736(20)30211-7

5. Boscolo-Rizzo P,Borsetto D, Spinato G, Fabbris C, Menegaldo A, Gaudioso Pet al. New onset of loss of smell or taste in household contacts of homeisolated SARS-CoV-2-positive subjects. Eur Arch Otorhinolaryngol. 2020;1-4 doi:10.1007/s00405-020-06066-9

6. Vaira LA, Salzano G, Fois AG, Piombino P,De Riu G. Potential pathogenesis of ageusia and anosmia in COVID-19 patients. IntForum Allergy Rhinol. 2020;10.1002/alr.22593. doi:10.1002/alr.22593

7. Linton NM, Kobayashi T, Yang Y, Hayashi K, Akhmetzhanov AR, Jung SM, et al. Incubation period and other epidemiological characteristics of 2019 novel coronavirus infections with right truncation: a statistical analysis of publicly available case Data. J Clin Med. 2020;9(2):538. Published 2020 Feb 17. doi:10.3390/jcm9020538

8. Meng L, Hua F,BianZ Coronavirus disease 2019 (covid-19): emerging and future challenges for dental and oral medicine. J Dent Res. 2020;99(5):481-7. doi:10.1177/0022034520914246

9. Passarelli PC, RellaE, Manicone PF,Garcia-Godoy F,D'Addona A. The impact of the COVID-19 infection in dentistry. Exp Biol Med (Maywood). 2020;1535370220928905. doi:10.1177/1535370220928905

10. Xu R, Cui B, Duan X, Zhang P,Zhou X, Yuan Q. Saliva: potential diagnostic value and transmission of 2019-nCoV. Int J Oral Sci. 2020;12(1):11. Published $2020 \mathrm{Ap}$ 17. doi:10.1038/s41368-020-0080-z

11. Samaranayake LP, Reid J, Evans D. The efficacy of rubber dam isolation in reducing atmospheric bacterial contamination. ASDC J Dent Child. 1989:56(6):442-4.

12. Mupparapu M, Kothari KRM. Review of surface disinfection protocols in dentistry: a 2019 update. Quintessence Int. 2019;50(1):58-65. doi:10.3290/j. qi.a41337

13. Kampf G, TodtD,Pfaender S, SteinmannE. Persistence of coronaviruses on inanimate surfaces and their inactivation with biocidal agents. J Hosp Infect. 2020;104(3):246-51. doi:10.1016/j.jhin.2020.01.022

14. World Health Organization. Infection prevention and control during health care when novel coronavirus (nCoV) infection is suspected [internet]. WHO 2020. [cited 2020 May 3]. Available from:https://www.who.int/publicationsdetail/infection-prevention-and-control-during-health-care-when-novelcoronavirus-(ncov)-infection-is-suspected-20200125. WHO/2019-nCoV/ IPC/2020

15. Centers for Disease Control and Prevention, Office of the Assistant Secretary for Preparedness and Response. COVID-19 Pandemic Planning Scenarios. [Internet]. [cited 2020 May 3]. https://www.cdc.gov/coronavirus/2019-ncov/ hcp/planning-scenarios.html.2020.

16. Giudice A, Barone S, Muraca D, Averta F, Diodati F, Antonelli A, etal. Can teledentistry improve the monitoring of patients during the covid-19 dissemination? a descriptive pilot study. Int JEnviron Res Public Health 2020;17(10):E3399. Published 2020 May 13. doi:10.3390/ijerph17103399

17. Greenhalgh T, Wherton J, Shaw S, Morrison C. Video consultations for covid-19. BMJ. 2020;368:m998. Published 2020 Mar 12. doi:10.1136/bmj.m998

18. Ekeland AG, Bowes A, Flottorp S. Methodologies for assessing telemedicine: a systematic review of reviews. Int J Med Inform. 2012;81(1):1-11. doi:10.1016/j. ijmedinf.2011.10.009

19. Estai $M$, Kanagasingam $Y$, Tennant M, Bunt S. A systematic review of the research evidence for the benefits of teledentistry. J Telemed Telecare. 2018:24(3):147-56. doi:10:1177/1357633X16689433

20. Irving M, StewartR, Spallek H, Blinkhorn A. Using teledentistry in clinical practice as an enabler to improve access to clinical care:a qualitative systematic review. J Telemed Telecare. 2018;24(3):129-46. doi:10.1177/1357633X16686776

21. To KKW, Tsang OTY, Yip CCY,Chan KH, Wu TC, Chan JMC et al. Consistent detection of 2019 novel coronavirus in saliva [published online ahead of print, 2020 Feb 12]. Clin Infect Dis. 2020;ciaa149. doi:101093/cid/ciaa149

22. Kohn WG, Collins AS, Cleveland JL, Harte JA, Eklund KJ, Malvitz DM etal Guidelines for infection control in dental health-care settings--2003. MMWR Recomm Rep. 2003;52(RR-17):1-61.

23. Peng X, XuX, Li Y,Cheng L, Zhou X, Ren B. Transmission routes of 2019-nCoV and controls in dental practice. Int J Oral Sci. 2020;12(1):9. Published 2020 Mar 3. doi:10.1038/s41368-020-0075-9

24. CarrouelF, Conte MP,Fisher J, Gonçalves LS, DussartC, Llodra JC, et al COVID-19: A recommendation to examine the effect of mouthrinses with $\beta$-cyclodextrin combined with citrox in preventing infection and progression.J Clin Med. 2020;9(4):1126. Published 2020 Apr 15. doi:10.3390/jcm9041126

25. Rautemaa R, Nordberg A, Wuolijoki-Saaristo K, Meurman JH. Bacterial aerosols in dental practice - a potential hospital infection problem? J Hosp Infect.2006 Sep;64:76-81. doi:10.1016/j.jhin.2006.04.011.

26. van Doremalen N, Morris DH, Holbrook MG, Gamble A, Williamson BN, Tamin A, et al. Aerosol and surface stability of sars-cov-2 as compared with SARSCoV-1.NEngl J Med. 2020;382(16):1564-7.doi:10.1056/NEJMc2004973

27. Stadnytskyi V,BaxCE,Bax A, Anfinrud P.The airborne lifetime of small speech droplets and their potential importance in SARS-CoV-2 transmission. Proc Natl Acad SciU S A. 2020;117(22):11875-7. doi:10.1073/pnas.2006874117

28. Discacciati JA, Sander HH, de Castilho LS, Resende VL. Verificação da dispersão de respingos durante o trabalho do cirurgião-dentista [Determination of the dispersion of microorganisms in the course of dental surgical activity]. Rev Panam Salud Publica. 1998;3(2):84-7. doi:10.1590/s102049891998000200003

29. de Amorim RG, Frencken JE, Raggio DP, Chen X, Hu X, Leal SC. Survival percentages of atraumatic restorative treatment (ART) restorations and sealants in posterior teeth: an updated systematic review and meta-analysis. Clin Oral Investig. 2018;22(8):2703-25. doi:10.1007/s00784-018-2625-5

30. Mickenautsch S, Frencken JE, van't HM. Atraumatic restorative treatment and dental anxiety in outpatients attending public oral health clinics in South Africa. J Public Health Dent.2007;67(3):179-84. doi:10.1111/j:1752-7325.2007.00017.x

31. de Menezes Abreu DM, Leal SC, Frencken JE. Self-report of pain in children treated according to the atraumatic restorative treatment and the conventional restorative treatment--a pilot study. J Clin Pediatr Dent. 2009;34(2):151-5. doi:10.17796/jcpd.34.2.9k67p78617126263

32 Banerjee A, Frencken JE, SchwendickeF, Innes NPT. Contemporary operative caries management: consensus recommendations on minimally invasive caries removal. Br Dent J. 2017;223(3):215-22. doi:10.1038/sj.bdj.2017.672

33. Schwendicke F,Frencken JE, Bjorndal L, Maltz M, Manton DJ, Ricketts D, etal. Managing carious lesions: consensus recommendations on carious tissue removal. Adv DentRes. 2016;28(2):58-67. doi:10.1177/0022034516639271 
34. Gurgan S, KutukZB, Cakir FY, Ergin E. A randomized controlled 10 years follow up of a glass ionomer restorative material in class I and class II cavities. J Dent 2020 Mar;94:103175. doi:10.1016/j.jdent.2019.07.013

35. Hutchison C, Cave V.10 year comparison of glass ionomer and composite resin restoration materials in class 1and 2 cavities. Evid Based Dent. 2019;20(4):1134. doi:10.1038/s41432-019-0059-9

36. Giray FE, Peker S, Durmus B, Kargül B. Microleakage of new glass ionomer restorative materials in permanent teeth. Eur J Paediatr Dent. 2014;15(2):122-6.

37. Ashwin R, Arathi R. Comparative evaluation for microleakage between Fuji-VII glass ionomer cement and light-cured unfilled resin: a combined in vivo in vitro study. J Indian Soc Pedod Prev Dent. 2007;25(2):86-7. doi:10.4103/09704388.33454

38. Baratieri LN, Ritter AV. Critical appraisal. To bevel or not in anterior composites. J Esthet Restor Dent. 2005;17(4):264-9. doi:10.1111/j.1708-8240.2005.tb00126.x

39. 39. Aida A, NakajimaM, Seki N, Kano Y, Foxton RM, Tagami J. Effect of enamel margin configuration on color change of resin composite restoration. Dent Mater J. 2016;35(4):675-83. doi:10.4012/dmj.2016-039

40. Giannini M, Makishi P,Ayres AP, Vermelho PM, Fronza BM, Nikaido T, etal. Self-etch adhesive systems: a literature review. Braz Dent J. 2015;26(1):3-10. doi:10.1590/0103-6440201302442

41. Suzuki S, Takamizawa T,Imai A, Tsujimoto A, Sai K, Takimoto M, etal. Bond durability of universal adhesive to bovine enamel using self-etch mode. Clin Oral Investig. 2018;22(3):1113-22. doi:10.1007/s00784-017-2196-x

42. Dietschi $D$, Fahl $N$ Jr. Shading concepts and layering techniques to master direct anterior composite restorations: an update. Br Dent J. 2016;221(12):76571. doi:10.1038/sj.bdj.2016.944

43. Romero MF.Esthetic anterior composite resin restorations using a single shade: Step-by-step technique.J Prosthet Dent. 2015;114(1):9-12. doi:10.1016/j. prosdent.2015.02.01

44. Influence of different etching modes on bond strength to enamel using universal adhesive systems. J Contemp Dent Pract. 2016;17(10):820-5. Published 2016 0ct 1. doi:10.5005/jp-journals-10024-1937
45. Prodan DA, Gasparik C,Mada DC, Miclăuș V,Băciut M, DudeaD. Influence of opacity on the color stability of a nanocomposite. Clin Oral Investig. 2015;19(4):867-75. doi:10.1007/s00784-014-1315-1

46. Kemaloglu H, Karacolak G, Turkun LS. Can reduced-step polishers be as effective as multiple-step polishers in enhancing surface smoothness?. J Esthet Restor Dent 2017;29(1):31-40. doi:10.1111/jerd.12233

47. Hokett SD, Honey JR, RuizF,Baisden MK, Hoen MM. Assessing the effectiveness of direct digital radiography barrier sheaths and finger cots. J AmDent Assoc. 2000;131(4):463-7. doi:10.14219/jada.archive.2000.0202

48. Gamoh S, Akiyama H, Maruyama H, Ohshita N, Nakayama M, Matsumoto K, etal. Compliance with infection control practices when taking dental x-rays: Survey of a Japanese dental school. Clin Exp Dent Res. 2018;4(5):158-66. Published 2018 Aug 2. doi:10.1002/cre2.124

49. Charuakkra A, Prapayasatok S, Janhom A, Verochana K, Mahasantipiya P. Infection control and patient discomfort with an alternative plastic barrier in intraoral digital radiography. Dentomaxillofac Radiol. 2017;46(2):20160253. do:10.1259/dmfr.20160253

50. American Academy of Pediatric Dentistry. Re-emergence pediatric dentistry practice checklist [Internet]. 2020. [cited 2020 May]. Available from:https:// www.aapd.org/globalassets/media/covid-19/aapd-practicechecklistpdf

51. Dye BA, Hsu KL, Afful J.Prevalence and measurement of dental caries in young children. Pediatr Dent. 2015;37(3):200-16.

52. Finucane $D$. Rationale for restoration of carious primary teeth: areview. Eur Arch Paediatr Dent. 2012;13(6):281-92. doi:101007/BF03320828

53. Feldens CA, Rodrigues PH, de Anastácio G, Vítolo MR, Chaffee BW. Feeding frequency in infancy and dental caries in childhood: a prospective cohort study. IntDent J. 2018;68(2):113-21. doi:10:1111/idj.12333

54. Rutala WA, Weber DJ. Disinfection and sterilization in health care facilities: what clinicians need to know. Clin Infect Dis. 2004:39(5):702-9. doi:10.1086/423182

55. Song X, Vossebein L, Zille A. Efficacy of disinfectant-impregnated wipes used for surface disinfection in hospitals: a review. Antimicrob Resist Infect Control 2019;8:139. Published 2019 Aug 19. doi:10.1186/s13756-019-0595-2

\section{Eduardo Bresciani}

(Corresponding address)

São Paulo State University (UNESP), Institute of Science and Technology,

Department of Restorative Dentistry, 777 Eng. Francisco José Longo Avenue,

12245-000, São José dos Campos, SP, Brazil.

Date submitted: 2020 May 31

E-mail: Eduardo.bresciani@unesp.br 